\title{
Kandinsky o la autoenunciación poética del cuadro
}

\author{
Mario MURGia ELIZALDE \\ Universidad Nacional Autónoma de México
}

Si (como el griego afirma en el Cratilo)

el nombre es arquetipo de la cosa,

en las letras de rosa está la rosa

y todo el Nilo en la palabra Nilo

Jorge Luis Borges, El gólem

Todo el mundo quiere entender el arte.

¿Por qué no tratar de entender el canto de un ave?

Pablo Picasso

En algún momento de su vida, Wassily Kandinsky confesó lo siguiente al recordar su primera reacción ante un cuadro de Monet:

$Y$ de repente vi un cuadro por primera vez. Aunque en el catálogo se decía que era un montón de heno, no pude reconocerlo, lo que me resultó embarazoso. Además pensaba que el artista no tenía derecho a pintar de forma tan poco clara. No me parecía bien que faltara el objeto. Pero, asombrado y confuso, me di cuenta de que el cuadro no sólo cautivaba, sino que se grababa en la memoria pasando ante mis ojos inesperadamente, lo tiene uno presente con todos sus detalles. Todo me resultaba incomprensible y no fui capaz de adivinar las consecuencias de aquella experiencia. Lo que me quedaba claro era la fuerza inesperada de la paleta, desconocida hasta entonces para mi, que sobrepasaba todos mis sueños. La pintura irradiaba fuerza y esplendor de cuento de hadas. Inconscientemente se desacreditaba al objeto como elemento pictórico inevitable.'

Como esta impresión y recuerdo de Kandinsky, el presente trabajo quiere ser literalmente un intento de respuesta ante las interrogantes de la pintura abstracta, no sólo del pintor ruso, sino del informalismo en general. Tan aven-

I Wassily Kandinsky, apud. Hajo DÜTCHING, Kandinsky, p. 10. 
turada tarea sería imposible de abordar si no fuera por una inusitada capacidad del observador de internizar sus encuentros con el arte, en particular con la pintura y con la poesía. Sí, la relación entre ambas es estrecha, y adquiere sentido y significación, en este caso, debido a la constante necesidad de referencia y respuesta misma a través de la palabra. La anterior confesión de Kandinsky es más que elocuente: el color y la virtual ausencia de forma definida, así como sus consecuencias en el espíritu, pueden sólo expresarse a través de la poesía del lenguaje. Y es precisamente aquí donde el espíritu de Kandinsky sobresale: sus instrumentos para tocar y explorar la sensibilidad individual son ambos, el pincel y la pluma.

Aquí se intentará aclarar que la abstracción de Kandinsky no responde a una necesidad de improvisación nacida de un momento, digamos, artísticamente pasional, sino también a un método estrictamente diseñado para formar una especie de gramática poético-pictórica a partir del color y su arreglo en la superficie del lienzo. Es así que el plano se convierte para Kandinsky en una página sobre la cual se ordenan sintácticamente las pinceladas con el fin de establecer un circuito de comunicación entre el espíritu de la obra y el espíritu del individuo que la observa absorto y, ¿por qué no?, también confuso, además de abstraído en su embeleso. El cuadro de Kandinsky no sólo evoluciona de un discurso figurativo a uno abstracto, sino que también se autoenuncia para, a su vez, obtener una autoenunciación similar (en términos emotivos e intelectuales) por parte del mismo observador-lector.

Nuestro propósito general, sin embargo, presupone cierta tarea previa de definición del cuadro y su gramática o, mejor dicho, su poética en el sentido más amplio de la palabra. Si hemos de encontrar un punto de apoyo en este aspecto, quizá tengamos que echar mano de un método un tanto paradójico en sí mismo, pero quizá igualmente eficiente dadas las circunstancias: la afirmación a través de la negación en la que la segunda engloba, en términos semánticos, a la primera. Siguiendo este razonamiento tenemos que "el pensamiento del habla, desde sus comienzos platónicos, postula [...] una distinción de la negación como operación interna al juicio, y la negación como actividad fundamental de la significación..." ${ }^{2}$ De esta manera, y aunque parezca trivial, el cuadro es el cuadro, en el caso de la abstracción de Kandinsky, y no otra cosa. La pregunta es, si esto es cierto, ¿por qué designar al cuadro como autoenunciado si, a fin de cuentas, la lengua es igualmente lengua y no otra cosa? La respuesta no es fácil. El paso de Kandinsky hacia la abstracción absoluta y, por ende, hacia la autoenunciación, presupone procesos artísticointelectuales paralelos a los que sigue la lengua en su propia enunciación y

2 Julia Kristeva, Semiótica 2, p. 60. 
en la creación poética. Es necesario aquí entrar en materia propiamente y aproximarnos a la cuestión por el camino —o apenas la entrada, quizá- de la figuración.

En el cuadro Gabriele Münter Kandinsky se encuentra muy cerca de la realidad circundante, lo cual resulta natural al tratarse de un retrato. Sin embargo, la obra satisface sus propias necesidades al convertirse en una especie de recreación del objeto pintado, en este caso, la dama que aparece en él. Me refiero a esta "satisfacción de necesidades" en un sentido estilístico: las pinceladas son más libres de lo que se requeriría en la pintura figurativa convencional (sin restarle importancia a esta última, por supuesto) y de esta manera se acerca a los recuerdos impresionistas del propio Kandinsky. El cuadro representa a Gabriele de tres cuartos frente a un fondo oscurísimo resaltado por diáfanos destellos de luz. El contraste entre el fondo y la blanquísima tez y ropaje de la dama hacen que su figura se proyecte hacia adelante y que ella se convierta en su propia significación. La dama se encuentra privada de movimiento en sí, pero toda su energía está concentrada en las pinceladas gruesas que la recorren y que parecen dar realce a unos ojos claros rebosantes de sentimiento. La dama está viva en sus propios ojos y se convierte así en un referente interno más que externo. Gabriele Münter, a pesar de su referente de carne y hueso en la realidad, se convierte en un signo propio y autorreferente: "el significado pertenece a la esfera de la acción humana y a la esfera del pensamiento humano, pues de hecho las dos esferas están inseparablemente conectadas entre sí". ${ }^{3}$ Es precisamente este carácter inseparable de la acción pictórico-lingüística (establecida por la referencia al exterior, por el cuadro mismo y, claro está, por su císulo) lo que nos hace intuir el paso de Kandinsky hacia la pintura que no está ligada a la realidad externa. Si tomamos algunos versos claramente "figurativos", dando así un salto a la poesía, este proceso quizá adquiera más transparencia. Lo siguiente está tomado de "Entresuelo" de Jaime Sabines: "Un espejo, un ropero, una silla, / ninguna estrella, mi cuarto, una ventana, / la noche como siempre, y yo sin hambre, / con un chicle y un sueño, una esperanza". ${ }^{4}$ Las referencias a la realidad son evidentes; al hablar del espejo, del ropero o de la silla ni siquiera hay que pensar en ellos o imaginarlos, los significados son tales en la palabra propia, esto es, en su significante. Sin embargo, es el contexto del poema lo que trae a la mente los semas ${ }^{5}$ que ocasionan el

${ }^{3}$ Adam Schaff, Introducción a la semántica, p. 271.

4 Jaime SABINES, "Entresuelo", en Nuevo recuento de poemas, p. 22.

5 "Un sema es un rasgo distintivo de un semema. Un semema es el conjunto de los semas, o sea, de los 'rasgos semánticos pertinentes' que generalmente se utilizan en 
proceso intelectual en su mayor parte, pero también imaginativo y emocional que se da detrás de la lectura del poema. Por ejemplo, el salto del chicle al sueño en el último verso enuncia una posibilidad de relación que puede existir sólo en el poema, de la misma manera en que Gabriele existe para nosotros sólo en el cuadro y a pesar de su figuración. Es en este momento que los lenguajes poético y pictórico se hermanan en una clara introspección. Por otro lado, el referente natural de un cuadro es siempre un obstáculo para el encuentro de lo espiritual en la pintura, al ser ésta un arte básicamente visual; luego entonces, Kandinsky inicia el desarroilo de técnicas que le permiten irrumpir en el alma del individuo-artista.

El experimento abstracto de Kandinsky resultó por demás dramático, tanto así que su primer acercamiento a la composición eminentemente cromática, El jinete azul (Der blaue Reiter, exposición de 1911), causó las más acaloradas polémicas. Y cómo no, si el espíritu improvisador del nuevo Kandinsky y del impacto visual de su pintura era complicado $y$, aparentemente, falto de sentido en la significación estricta de la palabra. Para definir esta revolución kandinskyana habrá que tener en mente la definición del artista que el pintor tuvo a partir de su despertar a la abstracción: "El artista es la mano que, mediante una u otra tecla, hace vibrar adecuadamente el alma humana". ${ }^{6} \mathrm{La}$ vibración no es otra cosa que el diálogo establecido entre el espectador y la obra misma y, como ya se sabe, el diálogo es imposible sin lenguaje: "El arte es el lenguaje que habla al alma de las cosas que para ella significan el pan cotidiano, y que sólo puede obtener de esa forma". ' La forma no es otra que aquella de la abstracción, por paradójico que esto pueda parecer.

Efectivamente, el propósito principal de Kandinsky parece ser la inmediata respuesta del observador ante la aparente falta de forma definida. Sin embargo, queda claro que esto resultaría imposible sin el pleno desarrollo de la obra en la mente del artista. En Cuadro con arco negro (Bild mit Schwarzem Bogen), la reacción y respuesta se logran mediante la composición de contrastantes manchas de color sobre el plano. Por una parte, la organización del cuadro reposa sobre cuatro ejes principales: en forma triangular se organizan una mancha azul-verde en la parte inferior izquierda, una forma casi cuadrangular color ocre en la parte superior central, y una forma rojo-

un lexema, esto es una palabra, considerada en un contexto, y una situación de comunicación“ (Helena BERISTÁIN, Diccionario de retórica y poética, p. 75). Aquí los semas son tanto poéticos como pictóricos al considerar la contemplación activa del cuadro como un acto eminentemente comunicativo.

${ }^{6}$ W. KANDINSKY, De lo espiritual en el arte, p. 45.

${ }^{7}$ Ibid., p. 105. 


$$
\mathbf{A}
$$




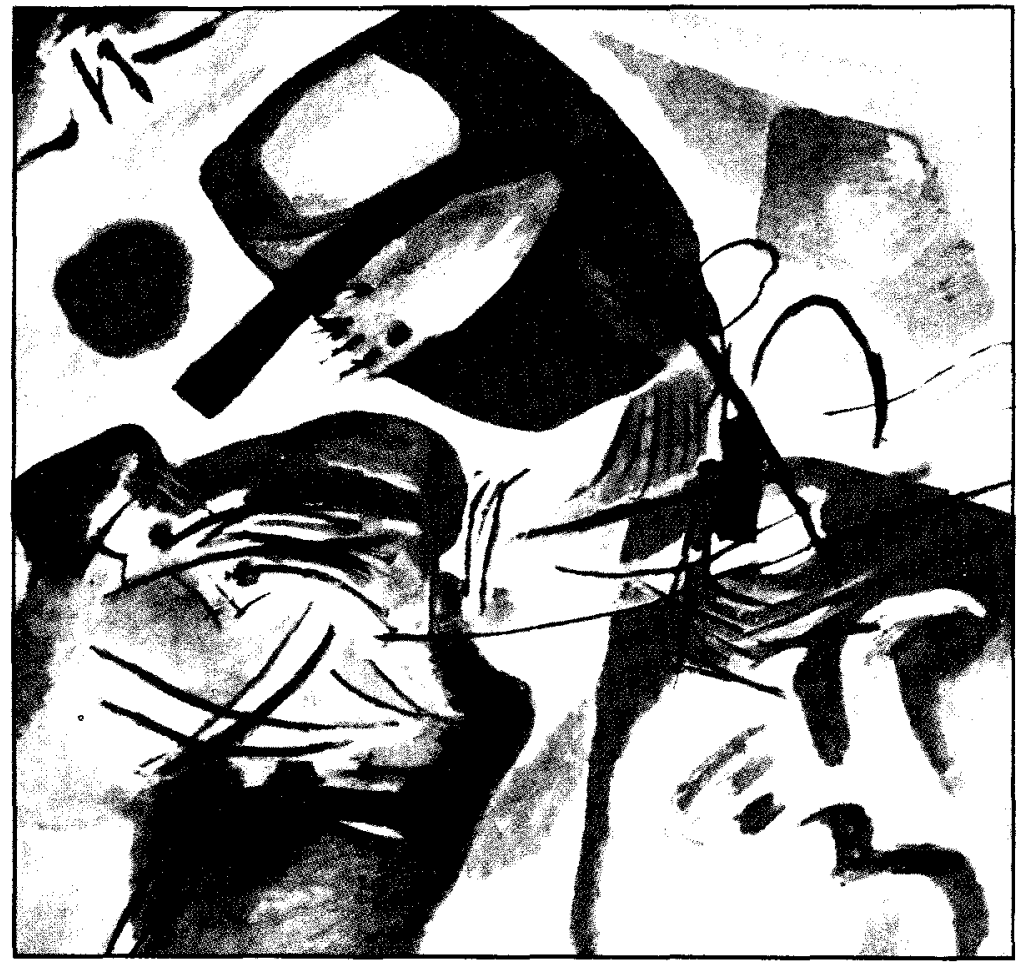

B) Cuadro con arco negro 


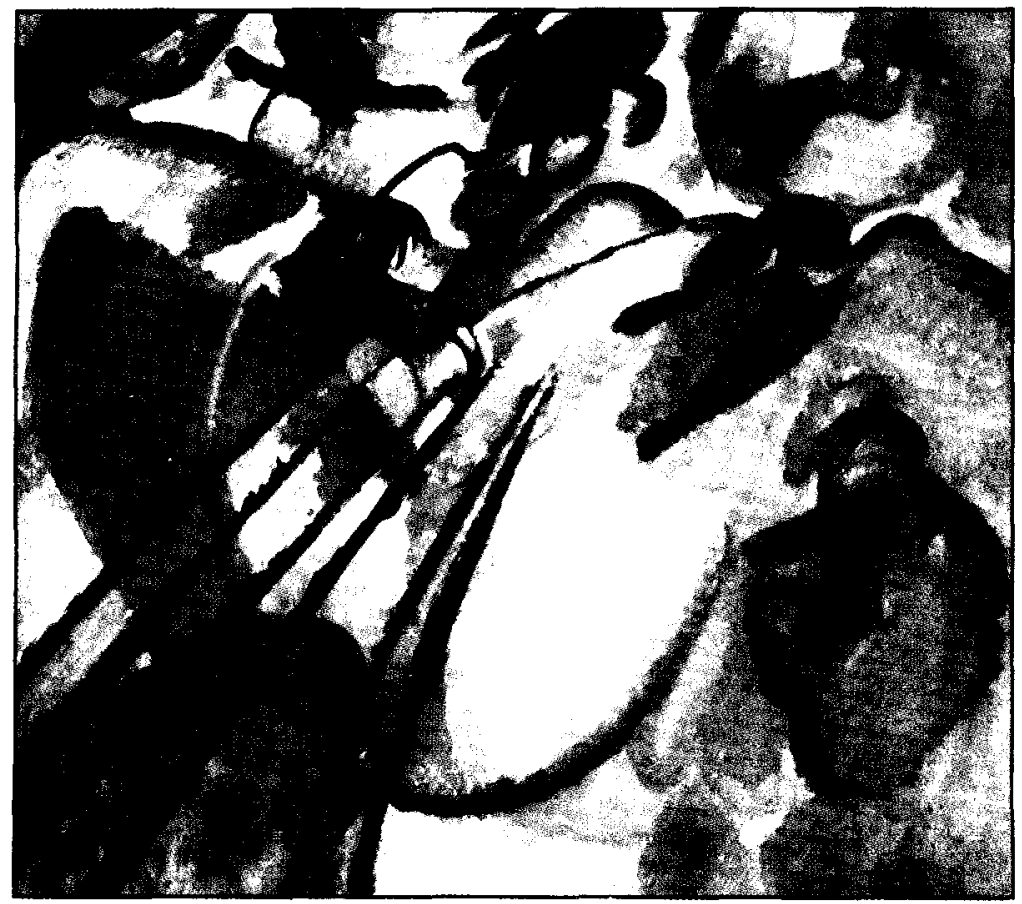

C) Improvisacion 26 (Remeros, 
A) Gabriele Münter, 1905

Óleo sobre lienzo, $45 \times 45 \mathrm{~cm}$

Städtische Galerie im Lenbachhaus,

Munich

B) Cuadro con arco negro, 1912

Óleo sobre lienzo, $188 \times 196 \mathrm{~cm}$

Musée National d'Art Moderne,

Centre Georges Pompidou,

París

C) Improvisación 26 (Remeros), 1912

Óleo sobre lienzo, $97 \times 107.5 \mathrm{~cm}$

Städtische Galerie im Lenbachhaus,

Munich 
naranja en la parte inferior derecha que se desvanece paulatinamente hasta formar una especie de media luna trunca. Estos centros cromáticos se encuentran, a su vez, atravesados por líneas finas en negro; líneas agresivas y rápidas que tensionan (al igual que el fondo claro con colores diáfanos que contrastan con los colores del "primer plano") las manchas de color más densas y llamativas que se encuentran al frente. Existen en el cuadro otras formas de color que, por decirlo así, "se mueven" alrededor de los tres ejes cromáticos principales, dándole así a la pintura un dinamismo inusitado. Por supuesto, la forma que sobresale por encima de todas es precisamente el arco negro, que comunica a dichos ejes entre sí y que les da unión y, sobre todo, cohesión. Es esta idea de organización en el aparente caos de la improvisación lo que provoca una respuesta súbita por parte del lector de la pintura, si es que a estas alturas ya se me permite llamarlo así. Lo llamo lector, porque, a pesar de los problemas de comprensión que la abstracción representa, la respuesta no se hace esperar; es decir, existe de hecho una intención y claro, una intensión: "Kandinsky formuló en este trabajo de la fase expresionista un tema básico dentro de su obra que, pasando por el periodo de la Bauhaus, permanecerá hasta la época tardía: el tema de la lucha y el conflicto". 8 Kandinsky mismo comentaría sobre este cuadro: "Nuestra armonía es una lucha de tonos, la estabilidad perdida, los principios en decadencia, inesperados redobles de tambor, aspiraciones sin meta alguna, un impulso aparentemente desgarrado y una añoranza, cadenas y lazos destrozados que convierten a muchos en uno solo, contradicciones y antagonismo". .9 aquí las palabras clave son "uno solo"; uno solo entre el artista, la obra y el observador y su respuesta. Claro está, todo esto resulta evidente en un proceso interno e individual que se ve apoyado por la palabra. La inclusión de "arco negro" en el título nos provoca asociaciones inevitables con lo circundante, pero es sólo en tanto que cuadro que estas asociaciones se vuelven significativas. He aquí que ambas organizaciones, la pictórica y la poética, se unen para originar la comprensión que se da a la par con la respuesta; he aquí que se dilucidan las funciones mismas de las dos gramáticas: "Toda gramática de una lengua proyectará el cuerpo finito y un tanto casual de locuciones observadas sobre un conjunto (que se supone infinito) de oraciones gramaticales". ${ }^{10}$ En Cuadro con arco negro las locuciones corresponden a los colores y líneas y, por su parte, el conjunto infinito de enunciaciones se da en términos de composición $y$ tensiones entre ellos.

${ }^{8}$ H. DÜTCHING, op. cit., p. 40.

${ }^{9} \mathrm{~W}$. KANDINSKY en ibid.

${ }^{10}$ Noam CHOMSKY, Estructuras sintácticas, p. 29. 
Lo anterior, sin embargo, nos remite al problema inicial de que, en principio y estrictamente hablando, el cuadro no es lengua ni la lengua cuadro. No obstante, los canales comunicativos que se establecen entre el cuadro mismo y el observador no hacen pensar más que en el proceso inherente a toda lengua; en este sentido, el artista se convierte en una suerte de disparador de la respuesta del público por medio de una introspección que se comunica y se sintetiza a través de y en el cuadro: "el autor llega a la admisión de que la obra, aunque sea considerada como objeto, existe no sólo como objeto, sino como una cosa que transmite otra cosa a alguien, por lo tanto como medio de comunicación"." Es aquí que se toca un tema de vital importancia para la pintura y la poesía: el objeto. En este rubro, el cuadro abstracto de Kandinsky se convierte en materia de sí mismo, de manera similar a como la palabra adquiere cuerpo además de volumen en la poesía. Tomemos los siguientes versos de Lorca:

Sí, tu niñez; ya fábula de fuentes.

El tren y la mujer que llena el cielo.

Tu soledad esquiva en los hoteles

y tu máscara pura de otro signo.

Es la niñez del mar y tu silencio

Donde los sabios vidrios se quebraban. ${ }^{12}$

Evidentemente, estos versos no son figurativos en el mismo sentido en que lo son los anteriores de Sabines. Si bien palabras como "mujer", "tren" o "vidrios" nos remiten a significados de la realidad, es sólo en su disposición en el poema que se liberan de ellos y se convierten en signos independientes de su referencia física, por llamarla de alguna manera. Después de todo, sería ocioso tratar de encontrar un referente para una "mujer que llena el cielo" o para unos "sabios vidrios". Sin embargo, la naturaleza particular del poema (y quizá del proceso racional que lo respalda) de alguna manera nos obliga a crear asociaciones que nos permitan una mejor comprensión de los versos. Esto en gran medida opaca la primera impresión y respuesta del lector ante las imágenes y signos que han sido construidos en el poema. A fin de cuentas, la poesía no es un arte visual (utilizando aquí nuevamente el principio de la negación como definición) y como lectores estrictos tratamos de entender el poema antes de siquiera poder otorgarle una respuesta visceral y sensorial. Por otro lado, no podemos olvidar que la pintura sí es ante todo un arte visual

"Omar Calabrese, El lenguaje del arte, p. 137.

12 Federico García Lorca, "Tu infancia en Menton", en Poeta en Nueva York, p. 114. 
y que el proceso de conocimiento y respuesta que se da ante ella depende en primera instancia de una impresión francamente obtenida a través del ojo. La tendencia a establecer relaciones con la realidad circundante se da después, sólo después de digerir sensorialmente el destello cromático.

El mejor ejemplo de esta respuesta seguida de reflexión ( $y$ no al revés) en la pintura de Kandinsky la podemos encontrar en Improvisación 26 (Remeros), de 1926. Al igual que en los versos de Lorca, cada signo se encuentra ensimismado y, por ejemplo, lo amarillo de la figura amarilla central es amarillo y no otra cosa, de la misma manera en que los diferentes tonos de rojo, verde y azul adquieren significación sólo en su propia disposición gramatical dentro del cuadro. En esta pintura tenemos que las tensiones están dadas por un arco color bermellón que atraviesa y, una vez más, comunica al menos tres de las figuras cromáticas que se disponen en un todo sostenido por un fondo en azul diáfano. Resulta claro que el punto álgido del cuadro se encuentra en seis diagonales negras que parten del centro de la pintura y que se disparan como intentando salir de ella hasta llegar al ángulo inferior izquierdo del plano. He aquí que nos encontramos con los remos, si hemos de reflexionar en el cuadro después de la primera impresión. Nótese que en este caso las asociaciones con objetos de la realidad son inevitables porque el cuadro tiene de hecho un título que nos remite a la figuración. La situación hubiese sido totalmente diferente si el cuadro se llamase sólo Improvisación 26, ya que el referente lingüístico trabajaría solamente en función de la disposición de la obra misma, y no de las disposiciones intelectuales que se dan inevitablemente a partir de un subtítulo más "corpóreo" como es el de Remeros. Roland Barthes ha dicho que "en la lingüística, la naturaleza del significado ha dado lugar a discusiones concernientes sobre todo a su grado de 'realidad'; sin embargo, estas discusiones están de acuerdo en insistir sobre el hecho de que el significado no es 'una cosa', sino una representación psíquica de la 'cosa'". ${ }^{3}$ Pero, ¿quién puede afirmar que esta representación psíquica de la cosa no es real en tanto que forma parte no sólo del cuadro mismo, sino de la percepción del observador-lector? La recreación de los colores, las imágenes y las palabras en la mente forma entonces un corpus imaginativo que se entiende como un circuito de comunicación.

Teniendo a Remeros en cuenta, vale la pena retomar algunas de las ideas de Kandinsky con respecto a la naturaleza de los colores:

El rojo, tal como nos lo imaginamos, un color ilimitado y cálido por excelencia, se comporta en nuestro interior como un color inquieto,

${ }^{13}$ Roland BARTHES, Elementos de semiología, p. 45. 
impulsivo y lleno de vida. No posee ese carácter irreflexivo propio del amarillo que parece disolverse hacia los extremos. A pesar de esa energía e intensidad, engendra una fuerza casi premeditada. Por asi decirlo, existe una cierta madurez en esa inquietud y pasión proyectadas hacia si mismo ${ }^{14}$ y no hacia el exterior.

El azul es el color típicamente celestial, [...] el elemento de la calma. [...] Crea una profundidad interminable en estados más graves donde no existe, ni puede existir, un final. ${ }^{15}$

Así, Kandinsky dota a sus colores de personalidad, fuerza y vitalidad para asegurarse de la recepción interna del observador. Sin embargo, esta prosopopeya ${ }^{16}$ (con toda su carga metafórica) se comprende sólo en relación con el cuadro una vez que se atestigua y se experimenta la improvisación gramatical de su composición cromática.

Es innegable que en la abstracción de Kandinsky el color y la palabra (en tanto que forma poético-pictórica) se entremezclan y, principalmente, se complementan. No es posible concebir el cuadro sin una organización previa que se obtiene no sólo al casar el color y la línea con el lienzo, sino también al volverse parte de la experiencia artística, emocional e intelectual del artista $y$, por supuesto, de aquel que lo contempla. Si la premisa de que el creador de arte ha de tocar las cuerdas más íntimas del observador ha de cumplirse, entonces el cuadro tendrá que desdoblarse en una función poética que sólo se puede alcanzar a través de la semiótica de la pintura y de la poesía. Los colores, las líneas y su gramática poética se convierten entonces en una vivencia que se experimenta únicamente al asomarse uno por la ventana infinita que abren, quizá por primera vez de forma consciente, Kandinsky y su abstracción. De esta manera, la comunicación entre obra pictórico-poética y lectorobservador se convierte en un juego de espejos: cada uno se autoenuncia una y otra vez hasta que se llega a la conclusión absoluta y definitiva de que el cuadro y el espíritu del individuo que despierta ante la contemplación de la obra de arte son ellos mismos y no otra cosa. Quizá sea conveniente que Kandinsky, una vez más mediante el uso de la palabra, concluya con su propia idea de la comunicación entre la obra y el espectador:

La pintura es un arte, y el arte en conjunto no significa una creación inútil de objetos que se desvanecen en el vacío, sino una fuerza útil

${ }^{14}$ Cursivas mías.

15 W. KANDinsKy apud. H. DÜtching; op. cit., p. 41.

16 Tropo mediante el cual se humaniza lo no humano o se anima lo inanimado (ver H. BERISTÁIN, op. cit., p. 309). 
para el desarrollo y la sensibilización del alma humana que apoya el movimiento del mencionado triángulo espiritual. ${ }^{17}[\ldots] \mathrm{El}$ artista ha de tener algo que decir, pues su deber no es dominar la forma, sino adecuarla a un contenido. ${ }^{18}$

Por supuesto, la definición de la poesía, lo poético y, claro está, el arte es casi tan inasequible como la identificación de aquella alma que Kandinsky insiste en traer a la luz una y otra vez. Como el intento de enunciación es ocioso, terminemos por decir que todas estas palabras de hecho se utilizan porque necesariamente intuimos que hay un significado (empezando por un sentido lingüístico) detrás de ellas. El cuadro, el poema y la poesía del cuadro son los responsables iniciales de esta intuición y del establecimiento inevitable de un diálogo con quien se encuentra frente a ellos. La responsabilidad del lector, como sin duda lo sabía Kandinsky, es quizá la utilización constante y entusiasta del código y discurso más apropiados.

\section{Bibliografía}

BARTHES, Roland, Elementos de semiología. Madrid, Alberto Corazón Editor, 1971 .

BERISTÁin, Helena, Diccionario de retórica y poética. México, Porrúa, 1972.

Calabrese, Omar, El lenguaje del arte. Barcelona, Paidós, 1987. (Instrumentos Paidós)

СНОMSкY, Noam, Estructuras sintácticas. México, Siglo XXI, 1978.

DÜTCHING, Hajo, Kandinsky. Colonia, Taschen, 1993. Ils.

García LorCa, Federico, Poeta en Nueva York. México, Rey, 1994. (Letras Hispánicas)

KRISTEVA, Julia, Semiótica 2. Madrid, Espiral Ensayo, 1978.

\footnotetext{
17 Por supuesto, entre artista, cuadro y observador.

${ }^{18}$ W. KandinskY, op. cit., pp: 105-106.
} 
Kandinsky, Wassily, De lo espiritual en el arte. México, Premiá, 1985. (La nave de los locos)

SABINES, Jaime, Nuevo recuento de poemas. México, Joaquín Mortiz, 1996. (Biblioteca paralela)

SCHAFF, Adam, Introducción a la semántica. México, FCE, 1966.

\section{Fuentes secundarias}

KANDinsKY, Wassily, Cursos de la Bauhaus. Madrid, Alianza Forma, 1983. $188 \mathrm{pp}$.

PLEYNET, Marcelin, Système de la peinture. París, Éditions du seuil, 1977. $188 \mathrm{pp}$.

SAussure, Ferdinand de, Curso de lingüistica general. Buenos Aires, Losada, 1945. $378 \mathrm{pp}$. 